\title{
Allergic reactions during childhood vaccination and management
}

\author{
Elif Soyak Aytekin ${ }^{\oplus}$, Bülent E. Şekerel ${ }^{\oplus}$, Ümit M. Şahiner ${ }^{\odot}$ \\ Department of Pediatric Allergy, Hacettepe University Faculty of Medicine, Ankara, Turkey.
}

\begin{abstract}
Background. Vaccination is one of the most effective public health tools to prevent a variety of infectious diseases. However, concerns about vaccine related adverse effects cause difficulties in clinical practice.

Methods. This review was prepared based on the latest literature available in the PUBMED database in English language (as of March 2021), and all articles with the keywords pediatric vaccine, allergy, hypersensitivity, adverse reaction were evaluated to prepare the article.

Results. Vaccine related confirmed allergic reactions are rare in children, ranging between 0,65-1.45 cases per million vaccine doses. Most of the allergic reactions are self-limited local reactions although in some cases severe anaphylaxis with multisystem involvement can be observed. Allergic reactions may occur because of either the active component (the antigen) of the vaccine, or additional components, such as preservatives, adjuvants, antimicrobials, stabilizers and other substances. Finding the culprit allergen is necessary to prevent future exposure to the allergen and to use alternative vaccines if possible. Diagnosis is largely based on a detailed history and clinical manifestation; also in vivo and in vitro tests may be helpful.

Conclusions. In this review we provide information about hypersensitivity reactions to allergen components of childhood vaccines along with the diagnosis and management of vaccine allergy. Besides the tremendous benefits of vaccination for the health of children, we emphasized that the risk of adverse effects is rare and poses a negligible threat.
\end{abstract}

Kew words: allergy, anaphylaxis, child, hypersensitivity, vaccine.

Vaccination is effective for preventing a variety of infectious diseases that cause morbidity and mortality. Routine childhood immunization has made the greatest contribution to global health since the 20th century, and throughout that time, the routine childhood immunization schedule has been updated, with new additions of vaccines as well as revisions to the timing and dosing of well-established vaccines. However, vaccine related adverse events are reported in the general population, and cause hesitations and difficulties in clinical practice.

Adverse events after vaccination can be allergic or non-allergic, and both of these reactions can

Ümit Murat Şahiner

umsahner@yahoo.com

Received 5th May 2021, accepted 14th June 2021. be local or systemic (Table I). Serious adverse events after vaccination occur less frequently than one in 10,000 doses and may become evident after a new vaccine is in widespread use in the general population. ${ }^{1-3}$ Vaccine related true allergic reactions are rare, although reported possible allergic reactions to vaccines are frequent.

Local reactions are commonly non-allergic reactions such as pain, redness and swelling, that develops within hours and days at the vaccination site after immunization. Most vaccine related allergic reactions such as contact dermatitis, subcutaneous nodules and maculopapular exanthem, are local type IV hypersensitivity reactions that are triggered by activation of CD4+ and CD8+ specific T cells, in certain situations, monocytes, eosinophils, and 
Table I. Adverse reactions following immunization.

\begin{tabular}{lll}
\hline & Allergic reactions & Non-allergic reactions \\
\hline Local Reactions & Urticaria & Pain \\
& Angioedema & Swelling \\
Local eczema & Redness \\
& Allergic contact dermatitis & Abscesses \\
& Systemic urticaria, angioedema & Hypertrichosis \\
\hline Systemic reactions & Rhino conjunctivitis & Vasovagal syncope \\
& Bronchospasm & Irritability \\
& Anaphylaxis & Headache \\
& & Diarrhea \\
& & Muscle pain \\
\hline
\end{tabular}

neutrophils can also be involved (Fig. 1). These reactions usually occur more than 12 hours after vaccination.

Vaccine related systemic allergic reactions are mostly type 1 hypersensitivity reactions, that may be life-threatening. The symptoms occur rapidly due to releasing of vasoactive mediators by mast cells and basophils (Fig. 2). Bohlke et al. ${ }^{4}$ reported 5 cases of anaphylaxis after administration of $7,644,049$ vaccine doses, for a risk of 0.65 cases/million doses in a study population consisted of children and adolescents. McNeil et al. ${ }^{5}$ identified 18 cases of anaphylaxis after administration of 12,403,201 vaccine doses to $0-17$ age group, for an incidence rate of 1.45 cases per million vaccine doses. Non-allergic systemic reactions include fever, vasovagal syncope, and nonspecific symptoms, such as irritability, malaise, diarrhea, muscle pain and headache.

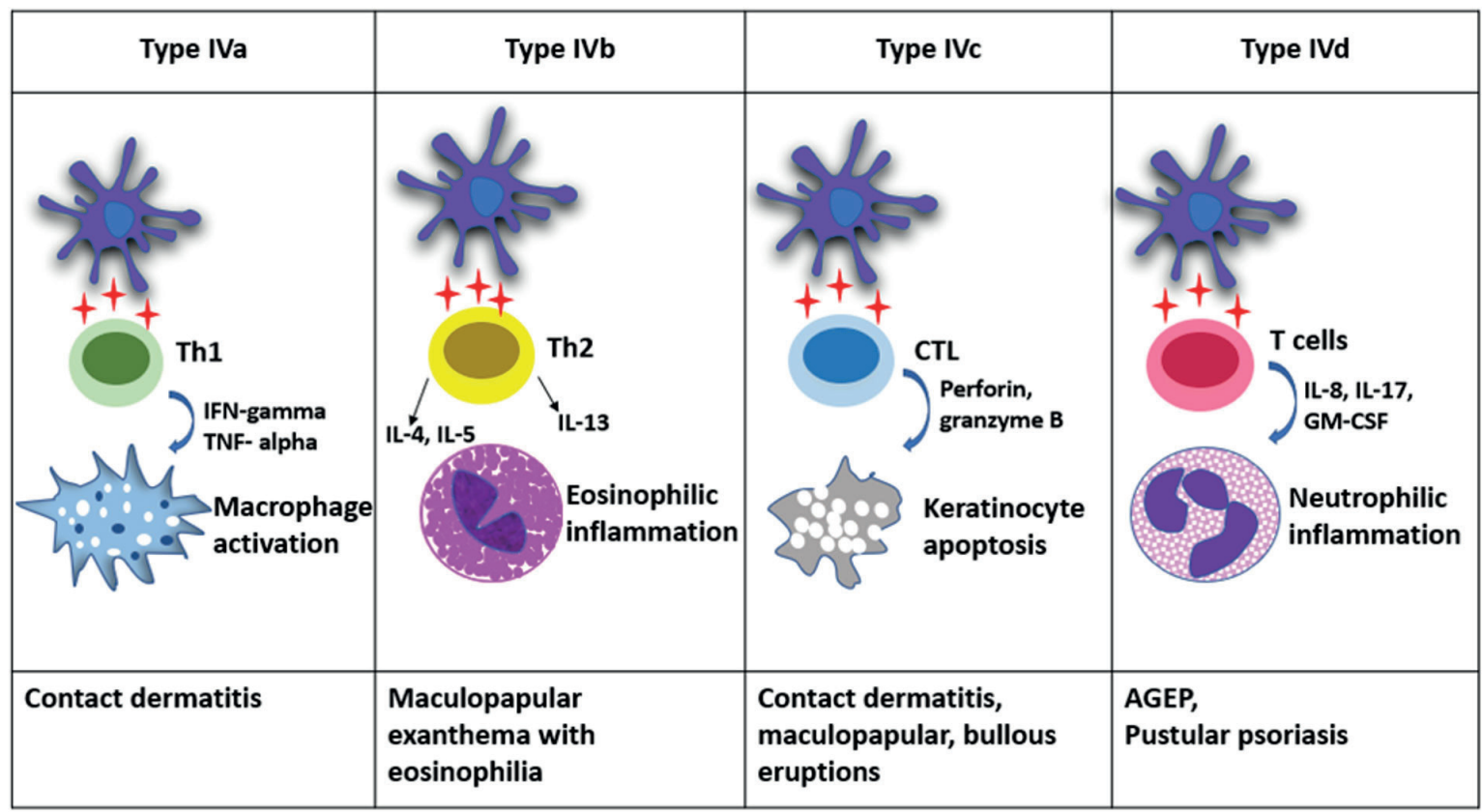

Fig. 1. T-cell mediated (type IV) hypersensitivity reactions. 


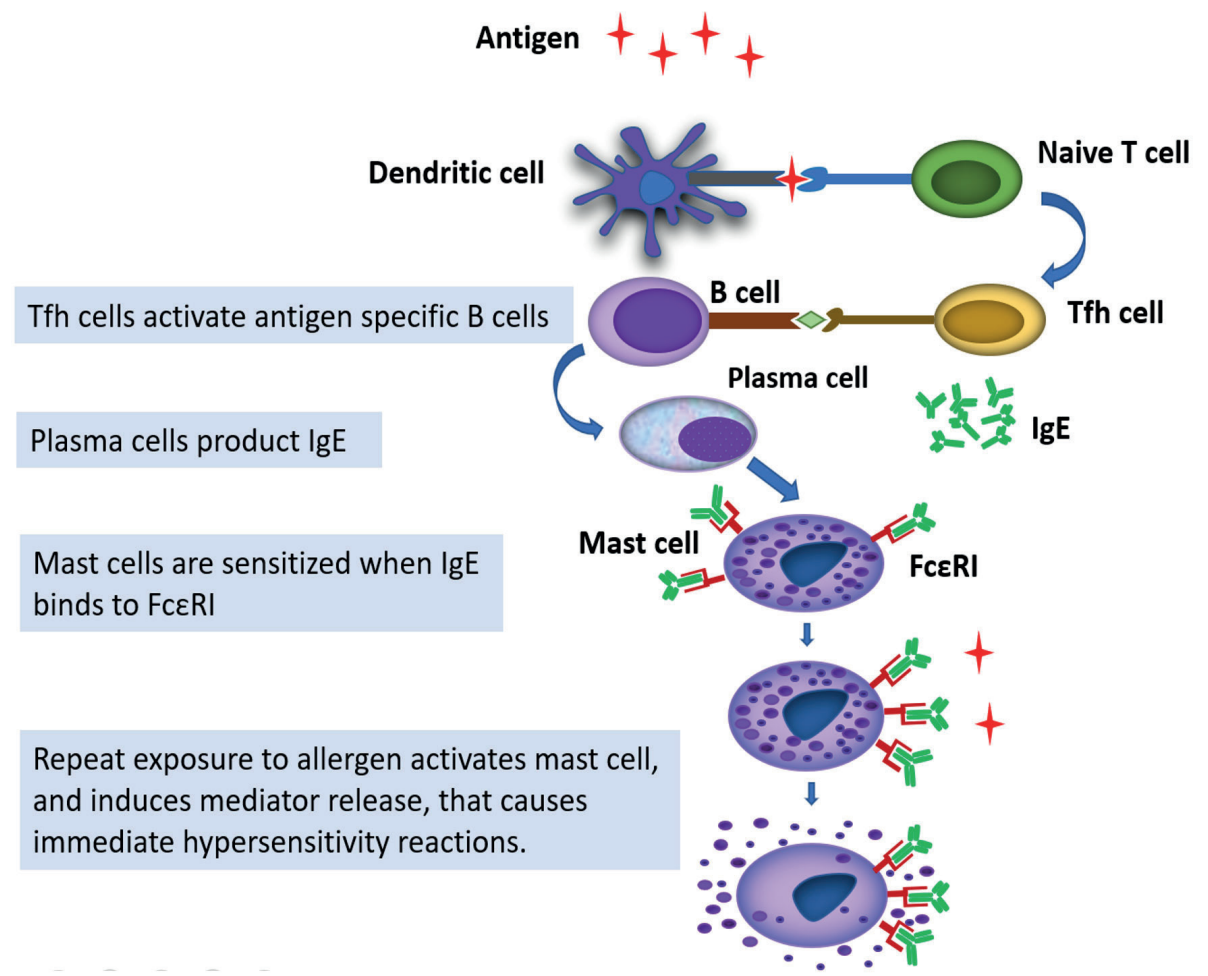

Fig. 2. Mechanism of type I hypersensitivity reactions.

\section{Allergic Reactions to Vaccine Components}

Vaccines contain an active component (the antigen), and additional components, such as preservatives, adjuvants, antimicrobials, stabilizers and other substances. (Table II)

\section{a. Microbial Antigen}

Microbial antigens, which induce the immune response, rarely can cause hypersensitivity reactions. Delayed urticaria, angioedema and skin rash were reported in patients receiving vaccines containing toxoids and pneumococcal antigens. ${ }^{6}$ However, most of these hypersensitivity reactions were not confirmed by allergy testing.

\section{b. Gelatine}

Gelatine is an animal protein derived from bovine or porcine, and found in drugs, cosmetic products and foods, such as desserts and sweets. Gelatine is also used as a stabilizer in live and inactivated vaccines, including MMR, chicken box, varicella, DTP and Japanese encephalitis. MMR, rabies, varicella-zoster, oral typhoid contain the highest concentrations of gelatine whereas DTP and influenza vaccines contain less, and vaccines with higher gelatine concentration carry higher allergy risks. ${ }^{78}$

In children, both immediate and nonimmediate systemic allergic reactions were reported with gelatine containing vaccines such as anaphylaxis, urticaria, systemic and local eruptions..$^{9-11}$ Prevalence of gelatine allergy appears to be higher in Japanese children, perhaps due to HLA DR 9, common in that population. ${ }^{12}$ Administration of the vaccines containing gelatine may also cause secondary food allergy to gelatine in 20 to $25 \%$ of children. ${ }^{9,13}$ Alpha-gal syndrome is known with delayed anaphylaxis to mammalian meat and gelatine-based products. Children allergic to red meat have a higher risk of gelatine allergy. ${ }^{14}$ Recently, gelatine related anaphylaxis after vaccination was reported in a 5 year old patient with alpha-gal syndrome. ${ }^{15}$ 
Table II. Childhood vaccines and allergic components.

\begin{tabular}{|c|c|}
\hline Hepatitis B & Aluminium, yeast, latex, formaldehyde, polysorbate 80 \\
\hline DTaP & $\begin{array}{l}\text { Casein, aluminium, 2-phenoxyethanol, yeast, latex, neomycin, polymyxin B, streptomycin, } \\
\text { formaldehyde, polysorbate } 80\end{array}$ \\
\hline Rotavirus & fetal bovine serum, polysorbate 80 , dextran, sorbitol, latex \\
\hline OPV & 2-phenoxyethanol, neomycin, polymyxin B, streptomycin, formaldehyde, lactalbumin \\
\hline Pneumococcal & Yeast, peptone, polysorbate 80 , aluminium \\
\hline Meningococcal & Casein, aluminium, yeast, latex, kanamycin, formaldehyde, polysorbate 80 \\
\hline MMR & Gelatine, albumin (hen's egg), neomycin, dextran \\
\hline Influenza & $\begin{array}{l}\text { Gelatine, albumin (hen's egg), casein, 2-phenoxyethanol, thimerosal, latex, neomycin, } \\
\text { polymyxin B, kanamycin, gentamycin, formaldehyde, polysorbate } 80\end{array}$ \\
\hline Varicella & Neomycin, gelatine \\
\hline Hepatitis A & Aluminium, yeast, latex, neomycin, polymyxin, polysorbate 80 \\
\hline HPV & Aluminium, yeast, polysorbate 80 \\
\hline
\end{tabular}

Since gelatine was replaced with hydrolysed gelatine, allergic reactions to vaccines have decreased significantly. ${ }^{16}$ In patients with a suspicion of gelatine allergy, skin test and/or specific IgE to gelatine should be performed. If skin prick test (SPT) is negative, the vaccine can be given with a 60 minute observation at hospital. If SPT is positive, gelatine free vaccine can be given or the vaccine should be administered in graded doses to obtain desensitization. ${ }^{17}$

\section{c. Hen's egg}

Egg allergy is the most frequent food allergy in children and the prevalence range is about $50 \% 18,19$, and $50 \%$ of children with egg allergies do not tolerate eggs at 6 years of age..$^{20-22}$ Many vaccines contain various amounts of egg protein, ovalbumin, such as MMR, influenza, rabies and yellow fever. Egg protein concentrations are higher at vaccines cultured in embryonic eggs (influenza, yellow fever, rabies), and lower at vaccines cultured in chicken embryo fibroblast (MMR). European Union legislation has established $2 \mu \mathrm{g} / \mathrm{ml}$ as the maximum allowed egg protein concentration, which is considered safe in patients with a previous history of egg anaphylaxis. ${ }^{17}$ Although vaccines containing egg protein are considered a problem in egg allergic children, several studies have shown that these vaccines are well tolerated and the allergic reaction is similar to the general population. ${ }^{23,24}$ Anaphylaxis prevalence due to MMR vaccine was reported in 5,1-12,5 cases per one million doses ${ }^{5,25}$, and most of allergic reactions to MMR is observed in children without egg allergies. ${ }^{26}$ In 1,061 eggallergic children, including 335 with previous anaphylaxis to eggs, no systemic reactions were obtained but in about $1 \%$ mild reactions were reported with the influenza vaccine. ${ }^{27,28}$ All egg allergic children can receive egg protein containing vaccines. Due to low sensitivity and specificity, SPT is not recommended. Children with egg allergies can be MMR-immunized under standard conditions regardless of the severity of the allergic reaction. When influenza vaccine is planned, children with mild allergic reactions should be observed for 30 minutes in primary care after receiving the vaccine ${ }^{29}$, whereas children who report previous severe allergic reactions to eggs should receive the influenza vaccine under the supervision of a health care provider who is able to recognize and manage severe allergic reactions. ${ }^{30}$

\section{d. Cow's milk}

Cow's milk protein (casein), is used as stabilizer in DTaP, TDaP vaccines. Kattan et al. ${ }^{31}$ reported 8 children with a severe cow's milk allergy who reacted with anaphylaxis to booster doses of the DTaP and Tdap vaccines. In addition, oral polio vaccine contains a-lactalbumin, and 
in Argentina, four children with cow's milk allergies showed hypersensitivity reactions to oral polio vaccine in three million administered doses. ${ }^{32}$ However, most of children with severe milk allergies tolerate $\mathrm{DTaP}, \mathrm{TDaP}$ and $\mathrm{OPV}$, therefore, in children with cow's milk allergies, these vaccines are not contraindicated.

\section{e. Adjuvants}

Adjuvants are molecules, which enhance immunological response when combined with antigens. Aluminium salts (aluminium hydroxide or aluminium phosphate) are the most common adjuvants used in inactivated vaccines, such as DTP, hepatitis $A$ and B, Haemophilus influenza $B$ and conjugated pneumococci vaccines. To date, no immediate hypersensitivity reactions have been documented with adjuvants. However, several contact dermatitis (type IV hypersensitivity) due to aluminium was reported. Itching subcutaneous nodules (vaccination granulomas) and contact allergy to aluminium have been described after vaccination with DTP vaccines in Europe. ${ }^{33}$ In a prospective study of 4,758 children, 1,2\% developed an itching granuloma following vaccine administration containing adjuvants, and positive patch tests to aluminium was observed in most of the children. ${ }^{34}$ However, these reactions are not a contraindication for immunization, if possible alternative vaccines can be administered to prevent local reactions, otherwise the vaccine can be given according to general recommendation.

\section{f. Antimicrobials}

Small amounts of antibiotics are used in vaccines (MMR, oral polio, influenza) such as neomycin, gentamycin, polymyxin $\mathrm{B}$, streptomycin and amphotericin B, to prevent bacterial and fungal contamination during the vaccine manufacturing process. No vaccines contain beta-lactams or sulphonamides. Systemic and local allergic reactions with neomycin following MMR vaccination ${ }^{35,36}$ and anaphylaxis after rabies vaccine were reported. ${ }^{37}$

\section{g. Latex}

Nowadays most vaccines don't contain latex, however, vaccine's vial or syringe may have been contaminated with latex, and allergic reactions may rarely occur. Russel et al. ${ }^{38}$ reported that among 160,000 vaccine-associated adverse events, 28 were latex related immediate type hypersensitivity reactions. The most culprit vaccines were inactivated influenza and hepatitis B. If children have a history of severe allergic reaction to latex, alternative vaccines without risk of latex exposure should be administered.

\section{h. Yeast}

Vaccines, that are recombinant proteins (Hepatitis B, HPV vaccines), expressed in a culture of Saccharomyces cerevisiae (baker's yeast) may contain a trace amount of yeast protein. However, an immediate reaction to these vaccines can rarely happen in yeastallergic children. In the US, in more than 180,000 vaccine adverse reactions, only 15 were probable or possible anaphylaxis after vaccination of patients with a history of yeast allergies. Of these, 11 cases received hepatitis $B$ vaccine and 4 cases other vaccines. ${ }^{39} \mathrm{PCV}-13$, some meningococcal and oral typhoid vaccines also can contain yeast. ${ }^{17}$ Children with a history of severe yeast allergy, should undergo allergic evaluation before hepatitis $B$ and $H P V$ vaccine administration. ${ }^{39}$

\section{i. Preservatives}

Preservatives such as thiomersal, formaldehyde, 2-phenoxyethanol and phenol are usually added to vaccines to prevent bacterial or fungal growth or contamination.

Thimerosal has been used in influenza, DTaP, pneumococcus, meningococcus, hepatitis $\mathrm{B}$ vaccines and reported with contact allergy and rarely with systemic allergic reactions. Nowadays, all pediatric vaccines for children younger than 6 years in the U.S. do not contain thimerosal. ${ }^{40}$ After withdrawing thimerosal 
from pediatric vaccines, a decrease in contact dermatitis to thimerosal was observed. ${ }^{41}$

Formaldehyde is used in vaccines, such as poliovirus, influenza, hepatitis A-B, and diphtheria and tetanus vaccines, to inactivate toxins from bacteria and viruses. Formaldehydecontaining vaccines rarely can contribute to local or systemic contact dermatitis ${ }^{42,43}$, but no IgE-mediated reactions have been reported.

2-phenoxyethanol is used in influenza, DTaP, Tdap and polio vaccines ${ }^{44}$, and is well tolerated. However, allergic contact dermatitis rarely have been reported due to 2-phenoxyethanol hypersensitivity after vaccination with DTP. ${ }^{45}$

\section{j. Polysorbate 80}

Polysorbate 80 is used as a surfactant, stabiliser and emulsifier in the composition of cosmetics and medications, including vaccines such as HPV, hepatitis A-B, influenza, some pneumococcal and meningococcal vaccines. ${ }^{44}$ Despite the frequent use of polysorbate 80 in vaccines, to our knowledge, only one case of anaphylaxis was reported in a 17 year old girl, due to polysorbate 80 hypersensitivity after administration of quadrivalent human papilloma virus vaccine ${ }^{46}$, perhaps due to lack of knowledge about the underlying cause of the reaction in similar cases. Polysorbate 80 is also one of the potential causes of the allergic reactions to COVID-19 vaccines(PfizerBioNTech) as well as polyethylene glycol. ${ }^{47}$

\section{Childhood Vaccines}

\section{a) Hepatitis B vaccine}

Hepatitis B vaccine is in routine childhood vaccination schedules in many countries and a total of three injections are recommended in the first 6 months of life. Hepatitis $B$ vaccine consist of inactivated HBsAg particles that are obtained from yeast through recombinant DNA technology, and aluminium phosphate or aluminium hydroxide as adjuvant. Anaphylaxis in patients with Hepatitis B vaccine has been rarely reported, probably due to yeast and latex. ${ }^{39,48,49}$

\section{b) BCG vaccine}

Bacillus Calmette-Guérin (BCG) is a live attenuated vaccine containing Mycobacterium bovis that protects against miliary tuberculosis and tuberculosis meningitis up to a ratio of $80 \%$. According to the World Health Organization (WHO), the BCG vaccine is recommended to all healthy infants in tuberculosis endemic countries. Localized skin reactions following BCG vaccination are common and mostly associated with infection. Self-limiting, local hypersensitivity reactions and dextran associated anaphylactoid reactions have been rarely reported with BCG vaccine. ${ }^{50-52}$ In children with weakened immune systems, BCG vaccine may cause local infection at the vaccination site that can be misdiagnosed as allergy, this local infection may also spread to lymph nodes, and cause lymphadenopathy or miliary tuberculosis. ${ }^{53}$

\section{c) Diphtheria, tetanus and pertussis vaccine}

WHO recommends diphtheria, tetanus, and pertussis immunization(DTaP) given at 2, 4, and 6 months of age, and booster doses also should be administered at 12 to 15 months of age and again at 4-6 years of age. ${ }^{54}$ Tdap vaccine contains reduced diphtheria toxoid, and is used in adolescents and adults. Thereafter, booster doses are recommended every 10 years. The rate of immediate hypersensitivity reactions following DTaP vaccination is 1 cases per 50,000 doses..$^{49}$ Anaphylaxis is generally associated with tetanus and diphtheria toxoids. ${ }^{55,56}$ Also, Kattan et al. ${ }^{31}$ identified 8 children with severe milk allergy who reacted with anaphylaxis to Tdap or $\mathrm{DTaP}$ vaccines, which are processed in a broth derived from casein. However, most patients even those with severe milk allergy tolerate these vaccines, so in children with cow's milk allergies, these vaccines are not contraindicated. Aluminium related delayed hypersensitivity reactions (vaccination granulomas and contact allergy) have also been reported after DTaP 
vaccination. $^{33}$ In the 1990's children who received $\mathrm{DTaP}$, had hypersensitivity reactions with MMR vaccine because of DTP vaccine containing gelatine induced sensitization to gelatine. Therefore gelatine was removed from DTaP products as of $1999 .^{57}$

\section{d) Polio vaccine}

Both inactivated poliovirus vaccine (IPV) and live attenuated oral poliovirus vaccine (OPV) have been used worldwide for routine childhood immunization since 1950. A total of three doses IPV are recommended at 2, 4, and 6 to 18 months of age. WHO recommends 4 doses of OPV at birth, 6, 10 and 14 weeks. However, most European countries and the US don't use OPV vaccines after polio eradication. Risk of anaphylaxis after polio vaccine was reported 1,6 per one million doses. ${ }^{5}$ OPV may contain trace amounts of antibiotics and cow's milk protein. Children with cow's milk allergies may rarely experience immediate hypersensitivity reactions with the OPV vaccine. ${ }^{32}$

\section{e) Pneumococcal vaccines}

Thirteen valent pneumococcal conjugated vaccine (PCV13) is an inactivated vaccine and is routinely recommended for children at 2 , 4, 6 months of age and followed by a booster dose at 12 to 15 months of age. The 23 valent pneumococcal polysaccharide vaccine (PPSV23) contains purified capsular polysaccharide antigens of 23 serotypes and licensed for use in people $\geq 2$ years of age.

Allergic reactions to pneumococcal vaccines are rare. Anaphylaxis was reported in a 12 month old infant after PCV-13 vaccine administration due to its carrier protein- a mutant diphtheria toxin CRM(197). ${ }^{58}$ In addition, pneumococcal antigen, itself, may be responsible for anaphylaxis. 59,60 Contact allergy to aluminium have also been described with the Prevenar vaccine. ${ }^{34}$

\section{f) Meningococcal vaccines}

Current meningococcal vaccine formulations consist of quadrivalent meningococcal conjugate vaccines for serogroups $\mathrm{A}, \mathrm{C}, \mathrm{W}$, and $\mathrm{Y}$ (MenACWY) and monovalent vaccines (serogroup B). Quadrivalent meningococcal vaccines are recommended for adolescents, young adults, and for persons $\geq 2$ months of age who are at an increased risk for meningococcal disease. Meningococcal vaccines contain allergic components such as yeast, casein, aluminium and formaldehyde. ${ }^{44}$ However, to our knowledge, no allergic reaction has been reported with these vaccines.

\section{g) $M M R$}

Measles, mumps, and rubella combination vaccine (MMR) is a live attenuated and routine immunization which is recommended at 12 to 15 months of age and 4-6 years of age. The rate of anaphylaxis following MMR vaccination have been reported 5,1-12,5 cases per one million doses. ${ }^{5,25}$ MMR vaccine is cultured in chicken embryo fibroblast, and contains negligible or no egg protein. However, there has always been controversy surrounding vaccination of children with egg allergies, although most of the allergic reactions to MMR is observed with gelatine and neomycin and not with egg. ${ }^{35,61}$ Although several studies show that MMR vaccination is well tolerated and safe in children with egg allergies ${ }^{24,62}$, rare but severe allergic reactions have also been reported. ${ }^{63}$ European Academy of Allergy and Clinical Immunology recommends that egg-allergic patients can be MMR immunized under standard conditions (standard vaccine, full dose, no mandatory observation time) ${ }^{64}$ The British Society for Allergy and Clinical Immunology (BSACI) guidelines recommend that all children with egg allergies should receive routine MMR vaccination performed by their family doctor/ nurse, but in cases of documented anaphylaxis with the vaccine itself, children should be evaluated by an allergist. ${ }^{65}$

\section{h) Influenza}

Vaccines for influenza prevention include inactivated influenza vaccines (IIV) (trivalent and quadrivalent) and live attenuated influenza 
vaccines (LAIV). Both of these vaccines may be trivalent (two strains of influenza $A$ and one strain of influenza $B$ ) or quadrivalent (two strains of influenza A and two strains of influenza B). IIV is approved for use in children $\geq 6$ months of age, whereas LAIV is approved for use only in children $\geq 2$ years. Influenza vaccine related allergic reactions are rare, according to VAERS, rate of hypersensitivity reaction was 10.1 , and the rate of anaphylaxis was 0.8 per million doses after influenza immunization. ${ }^{66}$ Components in influenza vaccine may cause an allergic reaction such as, 2 phenoxyethanol, gelatine, ovalbumin (hen's egg), microbial antigen and formaldehyde. ${ }^{67}$ Nagao et al. $^{68}$ identified, IgE antibodies to influenza vaccine antigen and 2-phenoxyethanol were significantly increased in children after influenza vaccination, and this might have enhanced the allergic reaction. Formaldehyde related contact dermatitis and gelatine related anaphylaxis have also been reported in patients after influenza vaccination. ${ }^{8,42}$ Influenza vaccines generally contain egg protein (ovalbumin), because the vaccine virus is cultured in embryonated chicken eggs. However, several studies have shown that, both inactivated and live attenuated influenza vaccines are safe in children with egg allergies, even if the patient had severe anaphylactic reactions to eggs. ${ }^{23,27,28,69}$ American Academy of Allergy Asthma and Immunology and the American College of Allergy Asthma and Immunology and the American Academy of Pediatrics do not recommend any precautions for influenza vaccine administration to eggallergic patients regardless of the severity of the egg allergy ${ }^{70}$, whereas EAACI recommend that patients with egg allergies should only be immunized with low egg concentrated $(<0.12 \mu \mathrm{g} / \mathrm{mL})$ influenza vaccine, and patients with a previous anaphylaxis history with eggs should be vaccinated under the supervision of a healthcare professional who can recognize and manage anaphylactic reactions. ${ }^{64}$

\section{i) Varicella}

Varicella vaccine is a live attenuated vaccine and recommended at 12 to 15 months of age and 4 to 6 years of age. Anaphylaxis incidence due to varicella immunization was reported 3 cases per million doses. ${ }^{71}$ Varicella vaccine contains high gelatine content as a stabilizer, and gelatine specific hypersensitivity reactions were observed in children and adults. ${ }^{10,72,73}$ Anaphylaxis was also reported in a child with alpha-gal allergy, after varicella immunization. ${ }^{15}$ Neomycin is also involved in varicella vaccine, however to our knowledge, no allergic reactions have been documented.

\section{j) Hepatitis $A$}

Hepatitis A vaccine is an inactivated vaccine that is recommended to all children $\geq 12$ months of age before potential hepatitis A exposure. A live attenuated hepatitis A vaccine is also available in some countries (India, Nepal, Philippines and Chile) for children $\geq 18$ months of age. Hepatitis A vaccine contains many allergic components, however no allergic reaction has been seen after Hepatitis A immunization.

\section{k) Rotavirus}

Two live attenuated oral rotavirus vaccines are available. Pentavalent human-bovine rotavirus reassortant vaccinen(RV5) is administered in three doses at 2, 4 and 6 months of age whereas attenuated human rotavirus vaccine (RV1) in two doses at 2 and 4 months of age. Rotavirus vaccines have several allergic components, RV5 contains fetal bovine serum and polysorbate 80, and RV1 contains dextran and sorbitol. But, to our knowledge, no allergic reactions have been reported with rotavirus vaccines. RV1 oral applicator contains latex rubber, therefore RV1 should not be given to infants with a severe latex allergy and RV5 can be preferred for these patients as its dosing tube is latex-free. ${ }^{74}$ However, vaccination is recommended if RV1 is the only accessible vaccine, because the benefit 
of immunization is considered to be more important than the risk of an allergic reaction.

\section{l) $H P V$}

HPV vaccination is recommended for all children $\geq 9$ years of age. HPV vaccines contain synthetically manufactured viruses like particles and additional allergic components such as aluminium, yeast and polysorbate 80 . IgE mediated anaphylactic reaction incidence is 1.4 cases per million dose with bivalent HPV vaccine and 26 cases per one million dose with quadrivalent $\mathrm{HPV}$ vaccine. ${ }^{5,75}$

\section{Diagnosis}

Diagnosis of vaccine allergy is largely based on a detailed history and clinical manifestation. The time of onset and duration of the reaction (IgE mediated reactions occur in a few hours after immunization whereas, delayed reactions occur in days) the symptoms (for example anaphylaxis and urticaria/angioedema suggest an IgE mediated reaction, whereas contact dermatitis or maculopapular exanthem suggest a type 4 reaction), history of the previous allergic reaction and possible other allergen (drugs, foods, latex) exposure are important to identify the type of hypersensitivity reaction and the culprit allergen.

When there is a history of vaccine allergy, finding the culprit allergen is necessary, to prevent exposure with products containing this allergen, and to use alternative vaccines without this component, if available. Testing should be performed with allergic components of the suspected vaccines. In vivo and in vitro tests may be helpful. Skin testing can be performed if the patient's history is consistent with IgE mediated reactions. Firstly, SPT (undiluted) should be performed, a positive SPT is suggestive for an allergic reaction, but if negative, intradermal test (1:100 1:10 diluted) should be administered due to its high sensitivity for $\operatorname{IgE}$ associated reactions.
However, false positivity of intradermal tests may occur due to irritant reactions rather than allergic reactions. ${ }^{76}$

For nonimmediate reactions, in particular contact dermatitis, maculopapular exanthem, subcutaneous nodules, patch testing with culprit allergen, such as aluminium, thiomersal and antibiotics, may be used to identify type IV hypersensitivity reactions.

Specific IgE tests are available for only limited components such as hen's eggs (egg white and ovalbumin), cow's milk (alpha-lactalbumin, beta-lactoglobulin, casein and bovine serum albumin), gelatine, latex and thiomersal. It should be considered that, sensitivity and specificity of both skin tests and specific $\operatorname{IgE}$ tests have not been established to confirm or exclude vaccine allergies.

\section{Management}

The usual dose of vaccines can be administered keeping the patient under observation at last 30 minutes following vaccination in a facility, where anaphylaxis can be recognized and managed. All patients should be asked whether there have been an allergic reaction following prior vaccinations or if the patient has a known allergy such as medication, food, latex.

Patients with egg allergy (including anaphylaxis) can be immunized with MMR under standard conditions. If the patient has a non-anaphylactic allergic reaction to eggs, influenza vaccine may be also administered under standard conditions. For patients with an egg anaphylaxis history, influenza vaccine should be performed under the supervision of a healthcare professional who can recognize and manage anaphylactic reactions. When milk allergic patients are immunized, there is no need for special precautions.

If a patient has a suspected IgE mediated allergy with other vaccine components such as gelatine/ thiomersal/yeast/antibiotics/latex and requires 
a vaccine containing these culprit allergens, skin tests and specific IgE tests should be performed. If the results are negative, immunization can be performed in the usual manner, while a positive result requires the vaccine to be given in the form of fractionated doses.

If patients have a history of non-immediate local reactions (contact dermatitis or subcutaneous nodule) with vaccine, the culprit allergen can be established with patch testing. If patch testing is negative, alternative vaccines can be used which do not contain the allergen component, if available. If patch testing is positive/not possible, vaccination is not contraindicated, deep intramuscular administration of the vaccine is recommended to reduce local reactions. ${ }^{49}$

Patients with a history of anaphylaxis to a vaccine, should be administered alternative vaccines which do not contain allergen components (Fig. 3). Where this is not possible, a skin test should be performed with the vaccine. When SPT is negative, the vaccine can be administered in split doses, first $10 \%$ of the complete dose and then 30 minutes later, $90 \%$ of the dose. When SPT is positive, vaccine can be safely administered under observation using a desensitization protocol, graded dose of vaccine is administered at 15 minute intervals (at the start, $0.05 \mathrm{ml}$ of $1: 10$ dilution, then $0.05 \mathrm{ml}, 0.1 \mathrm{ml}$, $0.15 \mathrm{ml}, 0.2 \mathrm{ml}$, of a $0.5 \mathrm{ml}$ full-strength vaccine). ${ }^{77}$ However, desensitization protocol still carries a risk of anaphylaxis. After the last dose, patients should be kept under observation for 2 hours.

\section{Author contribution}

The authors confirm contribution to the paper as follows: study conception and design: UMS; literature search, interpretation of the knowledge and manuscript preparation ESA; contribution to the discussion and manuscript structuring BES. All authors reviewed the results and approved the final version of the manuscript.

\section{Conflict of interest}

All authors declare that there is no financial relationship or conflict of interest areas that need to be known regarding the study.

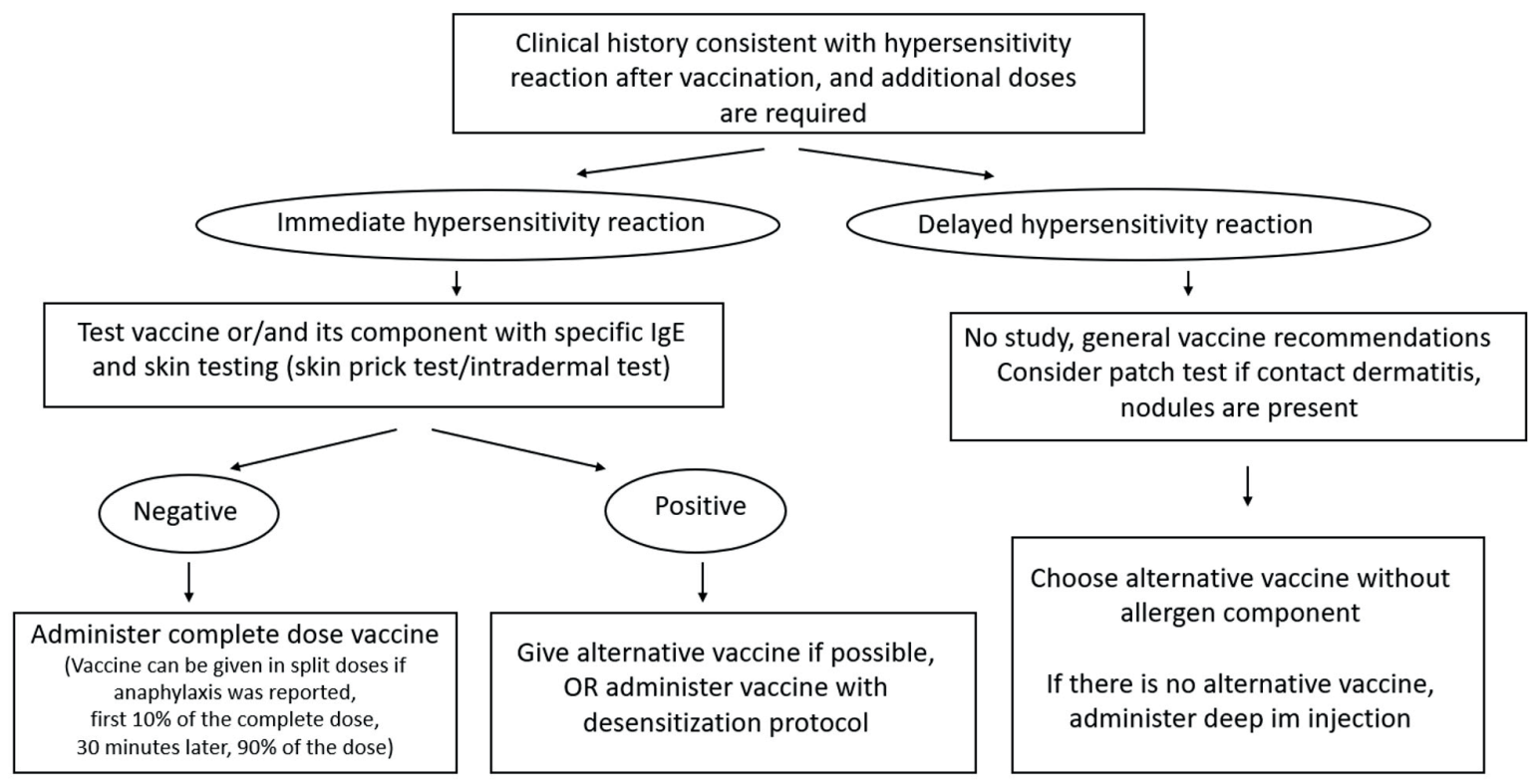

Fig. 3. Diagnosis and management of children with suspected vaccine allergy. 


\section{REFERENCES}

1. Murphy TV, Gargiullo PM, Massoudi MS, et al; for the Rotavirus Intussusception Investigation Team. Intussusception among infants given an oral rotavirus vaccine. N Engl J Med 2001; 344: 564-572. https://doi.org/10.1056/NEJM200102223440804

2. Simonsen L, Viboud C, Elixhauser A, Taylor RJ, Kapikian AZ. More on RotaShield and intussusception: the role of age at the time of vaccination. J Infect Dis 2005; 192(Suppl 1): S36-S43. https://doi.org/10.1086/431512

3. RothmanKJ, Young-XuY,ArellanoF.Agedependence of the relation between reassortant rotavirus vaccine (RotaShield) and intussusception. J Infect Dis 2006; 193: 898. https://doi.org/10.1086/500217

4. Bohlke K, Davis RL, Marcy SM, et al; Vaccine Safety Datalink Team. Risk of anaphylaxis after vaccination of children and adolescents. Pediatrics 2003; 112: 815-820. https://doi.org/10.1542/peds.112.4.815

5. McNeil MM, Weintraub ES, Duffy J, et al. Risk of anaphylaxis after vaccination in children and adults. J Allergy Clin Immunol 2016; 137: 868-878. https:// doi.org/10.1016/j.jaci.2015.07.048

6. Caubet JC, Ponvert C. Vaccine allergy. Immunol Allergy Clin North Am 2014; 34: 597-613. https://doi. org/10.1016/j.iac.2014.04.004

7. Kelso JM. Potential food allergens in medications. J Allergy Clin Immunol 2014; 133: 1509-1518. https:// doi.org/10.1016/j.jaci.2014.03.011

8. Lasley MV. Anaphylaxis after booster influenza vaccine due to gelatin allergy. Pediatr Asthma Allergy Immunol 2007; 20: 201-205. https://doi. org/10.1089/pai.2007.014

9. Sakaguchi M, Nakayama T, Inouye S. Food allergy to gelatin in children with systemic immediatetype reactions, including anaphylaxis, to vaccines. J Allergy Clin Immunol 1996; 98(6 Pt 1): 1058-1061. https://doi.org/10.1016/S0091-6749(96)80191-6

10. Miyazawa H, Inouye S, Sakaguchi M. Sensitization to gelatin in children with systemic non-immediatetype reactions to varicella vaccines. Ann Allergy Asthma Immunol 2000; 84: 341-344. https://doi. org/10.1016/S1081-1206(10)62784-6

11. Nakayama T, Aizawa C, Kuno-Sakai H. A clinical analysis of gelatin allergy and determination of its causal relationship to the previous administration of gelatin-containing acellular pertussis vaccine combined with diphtheria and tetanus toxoids. J Allergy Clin Immunol 1999; 103(2 Pt 1): 321-325. https://doi.org/10.1016/S0091-6749(99)70508-7
12. Kumagai T, Yamanaka T, Wataya $Y$, et al. A strong association between HLA-DR9 and gelatin allergy in the Japanese population. Vaccine 2001; 19: 32733276. https://doi.org/10.1016/S0264-410X(00)00555-7

13. Sakaguchi M, Yoshida M, Kuroda W, Harayama O, Matsunaga Y, Inouye S. Systemic immediate-type reactions to gelatin included in Japanese encephalitis vaccines. Vaccine 1997; 15: 121-122. https:/doi. org/10.1016/S0264-410X(96)00170-3

14. Mullins RJ, James H, Platts-Mills TA, Commins S. Relationship between red meat allergy and sensitization to gelatin and galactose- $\alpha-1$, 3-galactose. J Allergy Clin Immunol 2012; 129: 13341342.e1. https://doi.org/10.1016/j.jaci.2012.02.038

15. Stone Jr CA, Commins SP, Choudhary S, et al Anaphylaxis after vaccination in a pediatric patient: further implicating alpha-gal allergy. J Allergy Clin Immunol Pract 2019; 7: 322-324.e2. https:/doi. org/10.1016/j.jaip.2018.06.005

16. Zent O, Hennig R. Post-marketing surveillance of immediate allergic reactions: polygeline-based versus polygeline-free pediatric TBE vaccine. Vaccine 2004; 23: 579-584. https://doi.org/10.1016/j. vaccine.2004.07.016

17. Franceschini F, Bottau P, Caimmi S, et al. Vaccination in children with allergy to non active vaccine components. Clin Transl Med 2015; 4: 3. https://doi. org/10.1186/s40169-014-0043-0

18. Allen CW, Kemp AS, Campbell DE. Dietary advice, dietary adherence and the acquisition of tolerance in egg-allergic children: a 5-yr follow-up. Pediatr Allergy Immunol 2009; 20: 213-218. https://doi. org/10.1111/j.1399-3038.2008.00784.x

19. Eggesbø M, Botten G, Halvorsen R, Magnus P. The prevalence of allergy to egg: a population-based study in young children. Allergy 2001; 56: 403-411. https://doi.org/10.1034/j.1398-9995.2001.056005403.x

20. Sicherer SH, Wood RA, Vickery BP, et al. The natural history of egg allergy in an observational cohort. J Allergy Clin Immunol 2014; 133: 492-499. https://doi. org/10.1016/j.jaci.2013.12.1041

21. Yavuz ST, Sahiner UM, Buyuktiryaki B, et al. Phenotypes of IgE-mediated food allergy in Turkish children. Allergy Asthma Proc 2011; 32: 47-55. https://doi.org/10.2500/aap.2011.32.3481

22. Akarsu A, Ocak M, Koken G, Sahiner UM, Soyer $\mathrm{O}$, Sekerel BE. IgE mediated food allergy in Turkey: different spectrum, similar outcome. Turk J Pediatr 2021; 63: 554-563. https://doi.org/10.24953/ turkjped.2021.04.002 
23. Upton JEM, Hummel DB, Kasprzak A, Atkinson AR. No systemic reactions to influenza vaccination in egg-sensitized tertiary-care pediatric patients. Allergy Asthma Clin Immunol 2012; 8: 2. https://doi. org/10.1186/1710-1492-8-2

24. Carballo IC, Pastor MD, Zavala BB, Cano MS, de la Hoz Caballer B. Safety of measles-mumps-rubella vaccine (MMR) in patients allergic to eggs. Allergol Immunopathol (Madr) 2007; 35: 105-109. https://doi. org/10.1157/13106778

25. Cheng DR, Perrett KP, Choo S, Danchin M, Buttery JP, Crawford NW. Pediatric anaphylactic adverse events following immunization in Victoria, Australia from 2007 to 2013. Vaccine 2015; 33: 1602-1607. https://doi.org/10.1016/j.vaccine.2015.02.008

26. Khakoo G, Lack G. Recommendations for using MMR vaccine in children allergic to eggs. BMJ 2000; 320: 929-932. https://doi.org/10.1136/bmj.320.7239.929

27. Turner PJ, Southern J, Andrews NJ, Miller E, ErlewynLajeunesse M; SNIFFLE Study Investigators. Safety of live attenuated influenza vaccine in atopic children with egg allergy. J Allergy Clin Immunol 2015; 136: 376-381. https://doi.org/10.1016/j.jaci.2014.12.1925

28. Turner PJ, Southern J, Andrews NJ, Miller E, ErlewynLajeunesse M; SNIFFLE-2 Study Investigators. Safety of live attenuated influenza vaccine in young people with egg allergy: multicentre prospective cohort study. BMJ 2015; 351: h6291. https://doi. org/10.1136/bmj.h6291

29. Grohskopf LA, Olsen SJ, Sokolow LZ, et al; Centers for Disease Control and Prevention. Prevention and control of seasonal influenza with vaccines: recommendations of the Advisory Committee on Immunization Practices (ACIP)-United States, 201415 influenza season. MMWR Morb Mortal Wkly Rep 2014; 63: 691-697.

30. McNeil MM, DeStefano F. Vaccine-associated hypersensitivity. J Allergy Clin Immunol 2018; 141: 463-472. https://doi.org/10.1016/j.jaci.2017.12.971

31. Kattan JD, Konstantinou GN, Cox AL, et al. Anaphylaxis to diphtheria, tetanus, and pertussis vaccines among children with cow's milk allergy. J Allergy Clin Immunol 2011; 128: 215-218. https://doi. org/10.1016/j.jaci.2011.04.046

32. Parisi CAS, Smaldini PL, Gervasoni ME, Maspero JF, Docena GH. Hypersensitivity reactions to the Sabin vaccine in children with cow's milk allergy. Clin Exp Allergy 2013; 43: 249-254. https://doi.org/10.1111/ cea.12059

33. Bergfors E, Trollfors B. Sixty-four children with persistent itching nodules and contact allergy to aluminium after vaccination with aluminiumadsorbed vaccines-prognosis and outcome after booster vaccination. Eur J Pediatr 2013; 172: 171-177. https://doi.org/10.1007/s00431-012-1841-2
34. Bergfors E, Hermansson G, Kronander UN, Falk L, Valter L, Trollfors B. How common are long-lasting, intensely itching vaccination granulomas and contact allergy to aluminium induced by currently used pediatric vaccines? A prospective cohort study. Eur J Pediatr 2014; 173: 1297-1307. https://doi. org/10.1007/s00431-014-2318-2

35. Kwittken PL, Rosen S, Sweinberg SK. MMR vaccine and neomycin allergy. Am J Dis Child 1993; 147: 128-129. https://doi.org/10.1001/ archpedi.1993.02160260018005

36. Rietschel RL, Bernier R. Neomycin sensitivity and the MMR vaccine. JAMA 1981; 245: 571. https:/doi. org/10.1001/jama.1981.03310310017008

37. Huang S, Zhu Z, Cai L, et al. Analysis on the risks of severe adverse events in rabies post-exposure prophylaxis and appropriate decision-making procedure. Hum Vaccin Immunother 2019; 15: 21212125. https://doi.org/10.1080/21645515.2018.1533779

38. Russell M, Pool V, Kelso JM, Tomazic-Jezic VJ. Vaccination of persons allergic to latex: a review of safety data in the Vaccine Adverse Event Reporting System (VAERS). Vaccine 2004; 23: 664-667. https:// doi.org/10.1016/j.vaccine.2004.06.042

39. DiMiceli L, Pool V, Kelso JM, Shadomy SV, Iskander J, Team V. Vaccination of yeast sensitive individuals: review of safety data in the US vaccine adverse event reporting system (VAERS). Vaccine 2006; 24: 703707. https://doi.org/10.1016/j.vaccine.2005.07.069

40. FDA. Vaccines, Blood \& Biologics. Thimerosal and Vaccines.Availableat:https://www.fda.gov/vaccinesblood-biologics/safety-availability-biologics/ thimerosal-and-vaccines\#: :text=Thimerosal $\% 20$ in $\% 20$ Vaccines-, Thimerosal $\% 20$ as $\% 20$ a $\% 20$ Preservative, threatening $\% 20$ contamination $\% 20$ with\%20harmful\%20microbes (Accessed on July 3, 2013).

41. Dórea JG. Low-dose Thimerosal (ethyl-mercury) is still used in infants' vaccines: should we be concerned with this form of exposure? J Trace Elem Med Biol 2018; 49: 134-139. https://doi.org/10.1016/j. jtemb.2018.05.010

42. Kuritzky LA, Pratt M. Systemic allergic contact dermatitis after formaldehyde-containing influenza vaccination. J Cutan Med Surg 2015; 19: 504-506. https://doi.org/10.1177/1203475415582306

43. Ring J. Exacerbation of eczema by formalincontaining hepatitis B vaccine in formaldehydeallergic patient. Lancet 1986; 2: 522-523. https://doi. org/10.1016/S0140-6736(86)90397-1

44. Sampath V, Rabinowitz G, Shah M, et al. Vaccines and allergic reactions: the past, the current COVID-19 pandemic, and future perspectives. Allergy 2021; 76: 1640-1660. https://doi.org/10.1111/all.14840 
45. Georgitis JW, Fasano MB. Allergenic components of vaccines and avoidance of vaccination-related adverse events. Curr Allergy Rep 2001; 1: 11-17. https://doi.org/10.1007/s11882-001-0091-6

46. Badiu I, Geuna M, Heffler E, Rolla G. Hypersensitivity reaction to human papillomavirus vaccine due to polysorbate 80 . BMJ Case Rep 2012; 2012: bcr0220125797. https://doi.org/10.1136/ bcr.02.2012.5797

47. Banerji A, Wickner PG, Saff R, et al. mRNA vaccines to prevent COVID-19 disease and reported allergic reactions: current evidence and suggested approach. J Allergy Clin Immunol Pract 2021; 9: 1423-1437. https://doi.org/10.1016/j.jaip.2020.12.047

48. Lear JT, English JS. Anaphylaxis after hepatitis B vaccination. Lancet 1995; 345: 1249. https://doi. org/10.1016/S0140-6736(95)92039-0

49. Echeverría-Zudaire LA, Ortigosa-del Castillo L, Alonso-Lebrero E, et al. Consensus document on the approach to children with allergic reactions after vaccination or allergy to vaccine components. Allergol Immunopathol (Madr) 2015; 43: 304-325. https://doi.org/10.1016/j.aller.2015.01.004

50. Grange J. Complications of Bacille Calmette-Guerin (BCG) vaccination and immunotherapy and their management. Commun Dis Public Health 1998; 1: 84-88.

51. Rudin C, Günthard J, Halter C, Staehelin J, Berglund A. Anaphylactoid reaction to BCG vaccine containing high molecular weight dextran. Eur J Pediatr 1995; 154: 941-942. https://doi.org/10.1007/BF01957516

52. Pönnighaus J, Fine PE, Moreno C. Hypersensitivity to dextran in BCG vaccine. Lancet 1991; 337: 1039. https://doi.org/10.1016/0140-6736(91)92697-Z

53. Cuello-García CA, Pérez-Gaxiola G, Gutiérrez CJ. Treating BCG-induced disease in children. Cochrane Database Syst Rev 2013; 2013: CD008300. https://doi. org/10.1002/14651858.CD008300.pub2

54. Jacobson RM. Routine childhood vaccines given in the first 11 months of life. Mayo Clin Proc 2020; 95: 395405. https://doi.org/10.1016/j.mayocp.2019.06.007

55. Martín-Muñoz MF, Pereira MJ, Posadas S, SánchezSabaté E, Blanca M, Álvarez J. Anaphylactic reaction to diphtheria-tetanus vaccine in a child: specific IgE/ IgG determinations and cross-reactivity studies. Vaccine 2002; 20: 3409-3412. https://doi.org/10.1016/ S0264-410X(02)00228-1

56. Mayorga C, Torres MJ, Corzo JL, et al. Immediate allergy to tetanus toxoid vaccine: determination of immunoglobulin $\mathrm{E}$ and immunoglobulin G antibodies to allergenic proteins. Ann Allergy Asthma Immunol 2003; 90: 238-243. https://doi. org/10.1016/S1081-1206(10)62148-5
57. Kumagai T, Ozaki T, Kamada M, et al. Gelatincontaining diphtheria-tetanus-pertussis (DTP) vaccine causes sensitization to gelatin in the recipients. Vaccine 2000; 18: 1555-1561. https://doi. org/10.1016/S0264-410X(99)00441-7

58. Arroabarren E, Anda M, Sanz ML. Anaphylaxis to pneumococcal vaccine; CRM (197): novel cause of vaccine allergy. Pediatr Allergy Immunol 2016; 27: 433-437. https://doi.org/10.1111/pai.12548

59. Ponvert C, Ardelean-Jaby D, Colin-Gorski AM, et al. Anaphylaxis to the 23-valent pneumococcal vaccine in child: a case-control study based on immediate responses in skin tests and specific IgE determination. Vaccine 2001; 19: 4588-4591. https:// doi.org/10.1016/S0264-410X(01)00257-2

60. Ponvert C, Scheinmann P, de Blic J. Anaphylaxis to the 23-valent pneumococcal vaccine: a second explored case by means of immediate-reading skin tests with pneumococcal vaccines. Vaccine 2010; 28: 8256-8257. https://doi.org/10.1016/j.vaccine.2010.10.031

61. Rosloff D, Sundquist B. Gelatin-induced vaccine anaphylaxis misattributed to egg allergy. Ann Allergy Asthma Immunol 2018; 121(Suppl): S77. https://doi.org/10.1016/j.anai.2018.09.251

62. Andersen DV, Jørgensen IM. MMR vaccination of children with egg allergy is safe. Dan Med J 2013; 60: A4573.

63. Yavuz ST, Sahiner UM, Sekerel BE, Tuncer A, Kalayci $\mathrm{O}$, Sackesen C. Anaphylactic reactions to measlesmumps-rubella vaccine in three children with allergies to hen's egg and cow's milk. Acta Paediatr 2011; 100: e94-e96. https://doi.org/10.1111/j.16512227.2011.02165.x

64. Nilsson L, Brockow K, Alm J, et al. Vaccination and allergy: EAACI position paper, practical aspects. Pediatr Allergy Immunol 2017; 28: 628-640. https:// doi.org/10.1111/pai.12762

65. Clark A, Skypala I, Leech SC, et al; British Society for Allergy and Clinical Immunology. British Society for Allergy and Clinical Immunology guidelines for the management of egg allergy. Clin Exp Allergy 2010; 40: 1116-1129. https://doi.org/10.1111/j.13652222.2010.03557.x

66. Halsey NA, Griffioen M, Dreskin SC, et al; The Hypersensitivity Working Group of the Clinical Immunization Safety Assessment Network. Immediate hypersensitivity reactions following monovalent 2009 pandemic influenza A (H1N1) vaccines: reports to VAERS. Vaccine 2013; 31: 61076112. https://doi.org/10.1016/j.vaccine.2013.09.066

67. Coop CA, Balanon SK, White KM, Whisman BA, Rathkopf MM. Anaphylaxis from the influenza virus vaccine. Int Arch Allergy Immunol 2008; 146: 85-88. https://doi.org/10.1159/000112507 
68. Nagao M, Fujisawa T, Ihara T, Kino Y. Highly increased levels of IgE antibodies to vaccine components in children with influenza vaccineassociated anaphylaxis. J Allergy Clin Immunol 2016; 137: 861-867. https://doi.org/10.1016/j. jaci.2015.08.001

69. Kang JH. Effectiveness and safety of seasonal influenza vaccination in children with underlying respiratory diseases and allergy. Korean J Pediatr 2014; 57: 164-170. https://doi.org/10.3345/ kjp.2014.57.4.164

70. AAAAI. Egg Allergy and the Flu Vaccine. Available at: https://www.aaaai.org/tools-for-the-public/ conditions-library/allergies/egg-allergy-and-the-fluvaccine (Accessed on September 15, 2021).

71. Wise RP, Salive ME, Braun MM, et al. Postlicensure safety surveillance for varicella vaccine. JAMA 2000; 284: 1271-1279. https://doi.org/10.1001/ jama.284.10.1271

72. Kumagai T, Yamanaka T, Wataya Y, et al. Gelatinspecific humoral and cellular immune responses in children with immediate-and nonimmediatetype reactions to live measles, mumps, rubella, and varicella vaccines. J Allergy Clin Immunol 1997; 100: 130-134. https://doi.org/10.1016/S00916749(97)70204-5
73. Singer S, Johnson CE, Mohr R, Holowecky C. Urticaria following varicella vaccine associated with gelatin allergy. Vaccine 1999; 17: 327-329. https://doi. org/10.1016/S0264-410X(98)00209-6

74. Committee on Infectious Diseases; American Academy of Pediatrics. Prevention of rotavirus disease: updated guidelines for use of rotavirus vaccine. Pediatrics 2009; 123: 1412-1420. https://doi. org/10.1542/peds.2009-0466

75. Brotherton JM, Gold MS, Kemp AS, McIntyre PB, Burgess MA, Campbell-Lloyd S; New South Wales Health HPV Adverse Events Panel. Anaphylaxis following quadrivalent human papillomavirus vaccination. CMAJ 2008; 179: 525-533. https://doi. org/10.1503/cmaj.080916

76. Wood R, Setse R, Halsey N. Assessment of irritant skin test reactions to common vaccines. J Allergy Clin Immunol 2007; 119(Suppl): S271. https://doi. org/10.1016/j.jaci.2006.12.429

77. Kelso JM, Greenhawt MJ, Li JT, et al. Adverse reactions to vaccines practice parameter 2012 update. J Allergy Clin Immunol 2012; 130: 25-43. https://doi. org/10.1016/j.jaci.2012.04.003 